\title{
Final clinical outcome after interventional procedures in enteric perforations with peritonitis
}

\author{
Ashish Ahuja', Jasdeep Singh², Jaspreet Kaur², Ravinder Pal Singh' \\ Department of Surgery ${ }^{1}$, Department of Microbiology', \\ Dayanand Medical College and Hospital, Ludhiana, Punjab, India
}

\begin{abstract}
Background \& Objectives: Enteric fever is a major challenge in developing countries and perforation peritonitis is a major cause of morbidity and mortality. The main aim of this study was to compare and evaluate the various operative procedures performed in enteric perforation and to find out the ideal operative procedure (if any) in the treatment of enteric perforation with peritonitis.

Material \& Methods: The study was conducted over a period of $3 \& 1 / 2$ years ( 2 years retrospective and $1 \& 1 / 2$ years prospective) on 150 patients presenting with enteric perforation. All patients were treated as a surgical emergency and given broad-spectrum antibiotic coverage, naso-gastric aspiration, fluid and electrolyte management prior to surgery. Patients were kept on regular follow-up for the next 6 months after treatment.

Results: In our study, 93\% of the procedures belonged to one of the two categories i.e. ileostomy or primary closure. Ileo-tranverse bypass and resection-anastomosis were done in $4 \%$ and $3 \%$ of the patients respectively. The total mortality was $11 \%$ \& the incidence was more in ileostomy group (17.9\%) as compared to the primary closure group (6.7\%). The difference in mortality between the ileostomy and primary closure group reached least statistically significant value $(\mathrm{p}<0.1)$.

Interpretation and Conclusions: Aggressive resuscitation and early surgery is the key to successful management of enteric perforation. Primary closure should be the treatment of choice in enteric perforation. Ileostomy should be done if there are major risk factors for post-operative fecal fistula formation.
\end{abstract}

Keywords: Abdominal distension, Enteric fever, Pain abdomen, Perforation, Peritonitis

\section{INTRODUCTION}

Typhoid fever is an endemic disease in India and other tropical countries. The term 'enteric fever' includes both typhoid and paratyphoid fever and is caused by Salmonella Typhi \& Paratyphi A, B \& C. The primary source of infection is ingestion of food and water contaminated by human and animal wastes. ${ }^{1}$ Small intestinal perforations and gastrointestinal haemorrhage are the most common and dreadful complications of enteric fever. In the past, enteric perforation was considered almost fatal and up to 1960, most surgeons favoured conservative management. ${ }^{2} 1970$ onwards most

\section{Corresponding Author :}

Dr Ashish Ahuja

Assistant Professor

Department of Surgery

Dayanand Medical College and Hospital

Ludhiana (Punjab)

E-mail: ashishahuja17@yahoo.co.in surgeons have favoured surgical intervention in typhoid perforations. ${ }^{3}$ Various operative procedures were advocated by different authors, such as simple repair of perforation, ${ }^{4}$ repair of perforation with ileo-transverse colostomy, ${ }^{5}$ primary ileostomy,,${ }^{6,7}$ single layer repair with an omental patch, ${ }^{8}$ and resection and anastomosis. ${ }^{9}$ Even with such a variety of procedures, enteric perforation still has a high rate of morbidity and mortality. In this study in patients with enteric perforation, we have compared different operative procedure in terms of deviancy, overall morbidity and mortality.

\section{MATERIALS AND METHODS}

The study was conducted in the department of Surgery in a tertiary care hospital over a period of $3 \& 1 / 2$ year (retrospective for 2 years and prospective for $1 \& 1 / 2$ years). The main aim of this study was to compare and evaluate the various operative procedures performed in enteric perforation and to find out the ideal operative procedure (if any) in the treatment of enteric perforation 
with peritonitis. The prospective study group was kept on regular follow-up for the next 6 months. The diversion ileostomy group was called for ileostomy closure 6-8 weeks after the primary surgery. The study was not a controlled or randomized study, as the distribution of patients in each operative category was based on the decision of the operating surgeon, which in turn was based on: the duration of perforation and hemodynamic status of the patient; and per-operative findings like: number of perforations, site of the perforations, peritoneal contamination, gut-wall edema, friability and impending perforations. The provisional diagnosis of enteric perforation was based on history of fever, followed by acute onset of abdominal pain, with signs and symptoms of perforation peritonitis, along with radiological finding of pneumoperitoneum, supplemented by a positive Widal test. All patients were treated as a surgical emergency and given broad-spectrum antibiotic coverage, nasogastric aspiration, fluid and electrolyte management prior to surgery. The choice of operative procedure performed was made by the operating surgeon, guided by the abovementioned criteria. The various procedures were compared in terms of postoperative morbidity, mortality and hospital stay using various statistical methods like $\mathrm{Z}$ test (test of proportions) and t-test. Comparison between the four operative procedures was done based on the following parameters:

Morbidity factors- including post operative complications like wound infections, formation of fecal fistula, respiratory complications, post operative shock $\&$ acute renal failure (ARF).

Mortality rate, duration of hospital stay

Post operatively, naso-gastric aspiration, i/v fluids and broad spectrum antibiotics were continued. Naso-gastric tube was removed after the patient passed flatus, usually around $5^{\text {th }}$ post operative day. Oral sips of liquids were started around the $5^{\text {th }}$ or $6^{\text {th }}$ post-operative day, and patient shifted to full oral diet in the next few days.

\section{RESULTS}

In our study, the age of the patients ranged from 17 to 75 years and M:F ratio was 4.17:1 (Table I). Fever and abdominal pain were present in all cases. Other predominant symptoms were abdominal distension (92\%) and obstipation (88\%) (Figure I). X-ray abdomen (erect) showed air under the diaphragm in $89 \%$ of the cases. Lecucopenia ( $<4000 / \mathrm{cu} . \mathrm{mm}$.) was present in the majority $(61 \%)$ of cases in spite of peritonitis. In our study,
Table I

Age-wise distribution of patients

\begin{tabular}{lc}
\hline Age (Years) & Frequency (\%age) \\
\hline $11-20$ & $21(14)$ \\
$21-30$ & $54(36)$ \\
$31-40$ & $33(22)$ \\
$41-50$ & $20(13.3)$ \\
$51-60$ & $16(10.6)$ \\
$61-70$ & $4(2.6)$ \\
$71-80$ & $2(1.3)$ \\
\hline
\end{tabular}

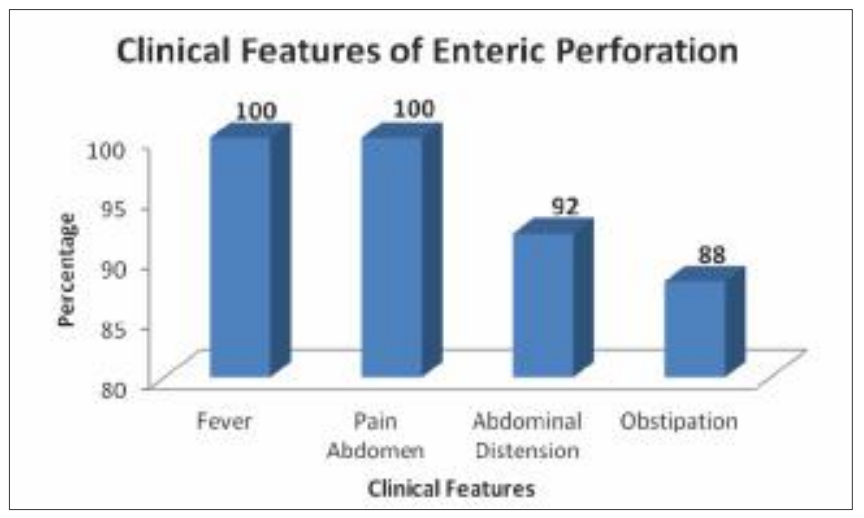

Figure I: Cinical features of enteric perforations

perforation occurred in the $1^{\text {st }}$ week of illness in $57 \%$ of the patients, $35 \%$ had a perforation in the $2^{\text {nd }}$ week of illness while, $8 \%$ perforated after 2 weeks of fever onset.

In our study, $93 \%$ of the procedures belonged to one of the two categories i.e. ileostomy or primary closure. The choice of operative procedure performed in each case was at the discretion of the operating surgeon, and was based on the general condition of the patient and the intra-operative findings. Ileo-tranverse bypass and resection- anastomosis were done in $4 \%$ and $3 \%$ of the patients respectively. The total mortality in our study was $11 \%$ the incidence of mortality was more in the ileostomy group (17.9\%) as compared to the primary closure group $(6.7 \%)$. In general, ileostomy was performed in patients who presented with shock at admission and more gut friability with impending perforations and gross peritoneal contamination, while primary closure was done in patients who had a healthier small gut with no impending perforations and less peritoneal contamination. Resection- 


\section{Table II}

\section{Comparison of Operative Procedures}

\begin{tabular}{|c|c|c|c|c|c|c|c|c|c|c|}
\hline \multirow[t]{3}{*}{ Procedure } & \multirow{3}{*}{$\begin{array}{l}\text { No. of } \\
\text { patients }\end{array}$} & \multicolumn{7}{|c|}{ Morbidity } & \multirow{3}{*}{$\begin{array}{l}\text { Mortality } \\
\text { (\%age) }\end{array}$} & \multirow{3}{*}{$\begin{array}{l}\text { Hospita } \\
\text { stay (in } \\
\text { days) }\end{array}$} \\
\hline & & \multicolumn{3}{|c|}{ Wound infection } & \multirow[b]{2}{*}{$\begin{array}{l}\text { Fecal } \\
\text { fistula }\end{array}$} & \multirow[b]{2}{*}{$\begin{array}{l}\text { Acute } \\
\text { renal } \\
\text { failure }\end{array}$} & \multirow[b]{2}{*}{$\begin{array}{l}\text { Respira } \\
\text { tory } \\
\text { Compli } \\
\text { cations }\end{array}$} & \multirow[b]{2}{*}{ Shock } & & \\
\hline & & Minor & Major & $\begin{array}{l}\text { Burst } \\
\text { Abdom } \\
\text { en }\end{array}$ & & & & & & \\
\hline Ileostomy & 95 & 27 & 6 & 10 & 1 & 7 & 28 & 16 & $7(17.9)$ & 16.54 \\
\hline $\begin{array}{l}\text { Primary } \\
\text { closure }\end{array}$ & 45 & 14 & 2 & 3 & 3 & 1 & 3 & 0 & $3(6.7)$ & 12.88 \\
\hline $\begin{array}{l}\text { Ileo- } \\
\text { transverse } \\
\text { bypass }\end{array}$ & 6 & 4 & 0 & 0 & 0 & 0 & 1 & 0 & $0(0)$ & 15.17 \\
\hline $\begin{array}{l}\text { Resection } \\
\text { anastomosis }\end{array}$ & 4 & 2 & 1 & 0 & 1 & 0 & 0 & 1 & $1(25)$ & 20 \\
\hline p value & - & 0.049 & 0.155 & 0.225 & 0.128 & 0.135 & 0.008 & 0.008 & 0.0932 & 0.034 \\
\hline
\end{tabular}

anastomosis was done in patients with multiple perforations, with less gut friability and relative hemodynamic stability. Ileo-transverse bypass was done in patients who met criteria for diversion ileostomy but were relatively stable hemodynamically. In our study, mortality occurred in 21 patients (11\%), 18 out of these deaths occurred within 7 days of surgery : 2 on the $1^{\text {st }}$ day, 5 on the $2^{\text {nd }}$ day, 5 more on the $3^{\text {rd }}$ day, rest 6 between $4^{\text {th }} \& 7^{\text {th }}$ day. Three mortalities occurred after more than 1 week of hospital stay. The difference in mortality between the ileostomy and primary closure group reached least statistically significant value $(\mathrm{p}<0.1)$. Most common causes of mortality (especially in early cases) were septicemia with shock and respiratory failure. ARF was commonly seen in these patients. Fecal fistula with septicemia was the causes of death in 1 patients, who expired after a hospital stay of 36 days. Complications occurred in $64 \%$ of the patients ( 36 out of 150 patients). Wound complications were the most common and occurred in $46 \%$ patients ( $31 \%$ minor, $6 \%$ major \& $9 \%$ burst abdomen).

The incidence of fecal fistula was maximum in the resection anastomosis group (25\%) followed by the primary closure group (6.7\%), and minimum in the ileostomy group $(1.05 \%)$. While the average hospital stay in all patients (excluding the expired patients) was 15.36 days, the hospital stay was longest in the resection anastomosis group i.e. 20 days. The average hospital stay was 16.5 days in the ileostomy group and 12.9 days in the primary closure group. The difference in hospital stay was statistically significant between all groups $(\mathrm{p}<0.05)$ (Table II).

\section{DISCUSSION}

Typhoid fever remains a major health problem in the developing countries. Among its various complications, enteric perforation is the most lethal and dreaded complication that the surgeons are confronted with. Early surgery is the best treatment option by consensus as it ceases the source of further faecal contamination of the peritoneal cavity. ${ }^{10}$

In our study, the age of the patients ranged from 17 to 75 years. The maximum number of patients, i.e. $36 \%$, were in the $3^{\text {rd }}$ decade. The patients in $2^{\text {nd }}, 3^{\text {rd }}, \& 4^{\text {th }}$ decades constituted $72 \%$ of all cases. This trend of age distribution was similar to that reported by other authors like Eggleston et al, ${ }^{11}$ Singh et al. ${ }^{7}$ In the present study M:F ratio was 4.17:1, that is consistent with the ratio 4:1 reported by Adesunkanmi et al. ${ }^{12}$ This is due to the fact that enteric fever is more common in males, possibly because of more exposure to infection.

Fever and abdominal pain were present in all cases. Other predominant symptoms were abdominal distension (92\%) and obstipation (88\%). Approximately $45 \%$ of the patients presented with shock at admission while 
tenderness, guarding or rigidity was present in all patients, abdominal distention was present in $96 \%$ patients, absent bowel sounds in $97 \%$ patients, and obliteration of liver dullness in only $53 \%$ of the patients. Abdominal pain, fever, and abdominal distention were the most common presenting symptoms in a study done by Nuhu et $a l^{13}$ while Salih Hosoglu et $a l^{14}$ reported abdominal pain, abdominal rigidity, relative bradycardia, and changes in consciousness as main clinical symptoms in their study on 80 patients.

Gas under diaphragm in X-ray abdomen (erect) is an important finding, and helpful in diagnosis. X-ray abdomen (erect) showed air under the diaphragm in $89 \%$ of the cases. Air under the diaphragm in enteric perforation has been reported in various studies with a variable rate of positivity i.e. $14.2 \%$ by Singh et $a l{ }^{7}$ $75 \%$ by Purohit et al. ${ }^{8}$

Similarly, TLC was done in all the patients and was abnormal i.e. either increased or decreased, in $75 \%$ of patients. Leucopenia ( $<4000 /$ cu.mm.) was present in the majority (61\%) of cases in spite of peritonitis in our study. It may be due to bone marrow depression by enteric toxaemia. Similarily, the most frequent laboratory finding was leukopenia (21 patients; 53 percent) in a study done by Salih Hosoglu et al. ${ }^{14}$

The widal test was positive in $32 \%$ (48/150) cases in our study. Whereas Eggleston et $a l^{11}$ and Khanna et $a l^{15}$ found a positive widal reaction in $95 \%$ and $58 \%$ of the patients respectively.

There was a positive correlation between duration of perforation at presentation and mortality. There was a significant increase in mortality with increase in duration of perforation $(\mathrm{p}<0.01)$. Previously, Archampong ${ }^{16,17}$ and Karmarker et al ${ }^{18}$ also observed a similar correlation duration of perforation and mortality. There was also a significant increase in hospital stay with increase in duration of perforation $(\mathrm{p}<0.01)$. This data suggests that early presentation of patients is one of the key factors in decreasing mortality in patients with enteric perforation.

Enteric perforation can occur at variable times after the onset of fever. In our study, perforation occurred in the $1^{\text {st }}$ week of illness in $57 \%$ of the patients, $35 \%$ had a perforation in the $2^{\text {nd }}$ week of illness while $8 \%$ had perforation after 2 weeks of fever onset. There was no significant correlation between fever-perforation interval and mortality in our patients. In Purohit's et al ${ }^{8}$ study,
$50 \%$ of the perforation occurred in the $1^{\text {st }}$ week of fever. Eggleston et $a l^{11}$ reported that $33 \%$ of the perforation occurred in the $2^{\text {nd }}$ week of fever. The duration of illness (fever-perforation interval) was within 14 days in 84 $(80.8 \%)$ patients in a study done by Chalya et al. ${ }^{19}$

The choice of operative procedure performed in each case was at the discretion of the operating surgeon, and was based on the general condition of the patient and the intra-operative finding. In our study, $93 \%$ of the procedures belonged to one of the two categories i.e. ileostomy or primary closure.

Ileostomies were further of 3 types:

1. Loop ileostomies, performed either through the perforation on proximally following primary closure of the perforation or resection anastomosis.

2. Double barrel ileostomies performed after ileal resection.

3. End ileostomies performed after ileal resection.

The ileostomies constituted $63 \%$ of the cases, while primary closures constituted $30 \%$, ileo-tranverse bypass and resection-anastomosis were done in $4 \%$ and $3 \%$ of the patients respectively. Since the patients in the latter two groups were small in number, the comparison of results was mainly done between the primary closure and the ileostomy groups. In a study done by Atamanalp et $a l^{20}$ on 82 patients of typhoid perforations, ileostomies were done on $39 \%$ of the cases, while primary closures were performed on $50 \%$ of the cases. In another study done on 62 cases by Zida et $a l^{21}$ primary ileostomy was done on $78.5 \%$ cases.

In general, ileostomy was performed in patients who presented with shock at admission, and had more gut friability with impending perforations and gross peritoneal contamination, while primary closure was done in patients who had a healthier small gut, with no impending perforations and less peritoneal contamination.

While the overall mortality in our study was $11 \%$, the mortality rate was more in the ileostomy group (17.9\%) as compared to the primary closure group $(6.7 \%)$. There was no mortality in the ileo-transverse bypass group i.e. 0 out of 6 patients, and 1 mortality in the resectionanstomosis group i.e. 1 out of 4 patients. The difference in mortality between the ileostomy and primary closure group reached least statistically significant value $(\mathrm{p}<0.1)$. The overall mortality rate in our study was comparable 
to other studies done on the setting of newer antibiotics and better intensive care facilities. In study done by Atamanalp et $a l^{20}$ the overall mortality was $11.0 \%$ (9 patients) while morbidity was highest in the ileostomy group. In contrast to our findings Malik et a ${ }^{22}$ reported $65 \%$ complication rate in primary closure of perforation in a study done on 112 cases.

The higher mortality seen in the ieostomy group could be attributed to the poor condition of the patients in this group with more hemodynamic instability and poor intraoperative findings. While our experience with resectionanastomosis was small, as only 4 patients underwent this procedure, result were not favorable, as 1 patient expired and another had a fecal fistula which required a relaparotomy and ileostomy. IIeo-transverse bypass, which was done in 6 patients, fared much better than resectionanastomosis, with no mortality and average hospital stay of 15 days, but larger series is required to evaluate its place in the treatment of enteric perforation.

The patients in ileostomy group had a significantly higher incidence of postoperative shock and respiratory complication compared to other groups, which may be partly attributable to higher incidence of shock at presentation and poor intra-operative findings in this subset of patients. The incidence of fecal fistula was maximum in the resection anastomosis group (25\%) followed by the primary closure group $(6.7 \%)$, and minimum in the ileostomy group (1.05\%). Shah et al ${ }^{23}$ reported $37.5 \%$ mortality with resection anastomosis. Thus in comparison with previous studies, mortality rates in our study were lower, especially in patients treated with a repair of the perforation. Fecal fistula is a very sinister complication as it increases the morbidity and mortality. Development of fecal fistula was unrelated to the operative procedure performed in a study done by Beniwal et al. ${ }^{24}$

While the average hospital stay in all patients (excluding the expired patients) was 15.36 days, the hospital stay was longest in the resection anastomosis group i.e. 20 days. The average hospital stay was 16.5 days in the ileostomy group and 12.9 days in the primary closure group. The difference in hospital stay was statistically significant between all groups $(\mathrm{p}<0.05)$. The patients with ileostomy had an added morbidity of ileostomy and an additional hospital stay $2^{\text {nd }}$ admission for ileostomy closure, which was not added in the comparison of hospital stay of primary admission. Our findings are in contrast to a study done by Malik et $a l^{22}$ which reported maximum stay in primary closure group, ranging from 3 weeks to 35 days of hospital stay.

In our study, complications occurred in $64 \%$ of the patients (36 out of 150 patients). Wound complications were the most common and occurred in $46 \%$ patients (31\% minor, $6 \%$ major \& $9 \%$ burst abdomen). Secondary suturing was done in patients with burst abdomen. Respiratory complications like pneumonitis, pleural effusion, ARDS \& respiratory failure were the $2^{\text {nd }}$ most common complication, and occurred in $22 \%$ of patients, and were associated with high mortality. Post operative shock and ARF occurred in $11 \%$ patients and were associated with very high mortality. Residual abscesses occurred in 8 patients $(5.33 \%)$ and were managed with I.V. antibiotics, and ultrasound-guided aspiration was done in 2 patients. In a study done by Khanna et al, ${ }^{15}$ postoperative complications encountered were wound infection in $74 \%$ patients, septicaemia in $44 \%$, gaped wound in $42 \%$, paralytic ileus in $22 \%$, respiratory complications in $18 \%$, burst abdomen in $10 \%$, bed sores in $8 \%$, subphrenic abscess in $5 \%$, faecal fistula in $4 \%$ and intestinal obstruction in $2 \%$ patients. Eight percent patients had to be re-explored for suspicion of reperforation, abscess formation and intestinal obstruction of which $4 \%$ died.

In our study, mortality occurred in 21 patients (11\%). 18 out of these deaths occurred within 7 days of surgery, 2 on the $1^{\text {st }}$ day, 5 on the $2^{\text {nd }}$ day, 5 on the $3^{\text {rd }}$ day, the rest 6 between $4^{\text {th }} \& 7^{\text {th }}$ day and 3 mortalities occurred after more than 1 week of hospital stay. Most common causes of mortality (especially in early cases) were septicemia with shock and respiratory failure. ARF was commonly seen in these patients. Fecal fistula with septicemia was the causes of death in 1 patient, who expired after a hospital stay of 36 days.

\section{CONCLUSIONS}

Early surgery and aggressive resuscitation is the key to successful management of patients with typhoid perforation. Primary closure should be the treatment of choice. Ileostomy should be done if there are major risk factors for post-operative fecal fistula formation. Primary ileostomy and repair of perforation with ileotransverse colostomy should be considered selectively in patients with multiple perforations, matted bowel loops and an unhealthy gut due to oedema and inflammation, resectionanastomosis should be avoided in these patients. 
Emphasis should be on preventive measures such as safe drinking water and appropriate sewage disposal, and typhoid vaccination.

\section{REFERENCES}

1. Singh S, Singh K, Grover AS, Kumar P, Singh G, Gupta DK. Two-layer closure of typhoid ileal perforations: a prospective study of 46 cases. Br J Surg 1995;82(9):1253.

2. Huckstep RL. Recent advances in the surgery of typhoid fever. Ann R Coll Surg Engl 1960;26:207-30.

3. Kim JP, Oh Sk, Jarrett F. Managemnt of Ileal perforation due to typhoid fever. Ann Surg 1975;181(1):88-91.

4. Bhansali SK. Gastrointestinal perforation: A clinical study of 96 cases. J Postgrad Med 1967;13:1-12.

5. Prasad PB, Choudhary DK, Prakash O. Typhoid perforation treated by closure and proximal side to side ileo-transverse colostomy. J Indian Med Assoc 1975;65:297-9.

6. Purohit PG. Surgical treatment of typhoid perforations: Experience of 1976 Sangli epidemic. Ind J Surg 1978;40: 227-38.

7. Singh KP, Singh K, Kohli JS. Choice of surgical procedure in typhoid perforation: experience in 42 cases. J Indian Med Assoc 1991; 89:255-6.

8. Kaul BK. Operative management of typhoid perforation in children. Int Surg 1975;60(8):407-10.

9. Athie CG, Guizar CB, Alcantara AV, Alcaraz GH, Montalvo E. Twenty-five years of experience in the surgical treatment of perforation of the ileum caused by Salmonella typhi at the General Hospital of Mexico City, Mexico. Surgery 1988; 123(6):632-6.

10. Ramachandran CS, Agarwal S, Dip DG, Arora V. Laparoscopic surgical management of perforative peritonitis in Enteric fever. A preliminary study. Surg Laparosc Endosc Percutan Tech 2004;14(3):122-4.

11. Eggleston FC, Santoshi B, Singh CM. Typhoid perforation of the bowel. Experiences in 78 cases. Ann Surg 1979; 190:31-5.
12. Adesunkanmi AR, Ajao OF: The prognostic factors in typhoid ileal perforation: a prospective study of 50 patients. J R Coll Surg Edinb 1997;42(6):395-9.

13. Nuhu A, Dahwa S, Hamza A. Operative management of typhoid ileal perforation in children. Afr J Paediatr Surg 2010;7(1):9-13.

14. Hosoglu S, Aldemir M, Akalin S, Geyik MF, Tacyildiz IH, Loeb M. Risk factors for enteric perforation in patients with typhoid Fever. Am J Epidemiol 2004;160(1):46-50.

15. Khanna AK, Misra MK. Typhoid perforation of the gut. Postgrad Med J 1984;60(706):523-5.

16. Archampong EQ. Operative treatment of typhoid perforation of the bowel. Br Med J 1969; 3:273-6.

17. Archampong EQ. Typhoid ileal perforations: why such mortalities? Br J Surg 1976; 63:317-21.

18. Karmarker SR, Trivedi DR, Bhalerao RA. Perforation of terminal Ileum. Ind J Surg 1972; 34:422-6.

19. Chalya PL, Mabula JB, Koy M, Kataraihya JB, Jaka H, Mshana SE, et al. Typhoid intestinal perforations at a University teaching hospital in Northwestern Tanzania: A surgical experience of 104 cases in a resource-limited setting. World J Emerg Surg 2012;8(7):4.

20. Atamanalp SS, Aydinli B, Ozturk G, Oren D, Basoglu M, Yildirgan MI. Typhoid intestinal perforations: twenty-six year experience. World J Surg 2007;31(9):1883-8.

21. Zida M, Ouedraogo T, Bandre E, Bonkoungou GP, Sanou A, Traore SS. Primary ileostomy for typhoid-related ileal perforation: a 62-case series in Ouagadougou, Burkina Faso. Med Trop (Mars). 2010;70(3):267-8.

22. Malik AM, Laghari AA, Mallah Q, Qureshi GA, Talpur AH, Effendi S, et al. Different Surgical Options and Ileostomy in Typhoid Perforation. World J Med Sci 2006;1(2):112-6.

23. Shah AA, Wani KA, Wazir BS. The ideal treatment of the typhoid enteric perforation-resection anastomosis. Int Surg 1999; 84:35-8.

24. Beniwal US, Jindal D, Sharma J, Jain S, Shyam G. Comparative study of operative procedures in typhoid perforation. Indian $J$ Surg 2003;65(2);172-7. 